Resenhas

\title{
ILAN PAPPÉ: HISTÓRIA E VERDADE
}

Berenice Bento ${ }^{1}$

\section{Resenha do livro:}

PAPPÉ, Ilan. A limpeza Étnica da Palestina. Editora Sundermann: São Paulo, 2016.

Há livros difíceis de serem lidos. Às vezes empacamos diante de conceitos ou de formulações rebuscadas. Há, também, outros tipos de dificuldades. Paramos a leitura para tomar ar, para dar ao pensamento tempo para se conectar com a narrativa de experiências históricas terríveis, devastadoras. Somos postos diante do precipício daquilo que chamamos "humanidade". Os crimes contra a humanidade nos arrancam do nosso lugar confortável e nos fazem pensar sobre os próprios sentidos que os criminosos dão ao "humano". Foi a conta-gotas que li A limpeza Étnica da Palestina (Editora Sundermann), do historiador israelense Ilan Pappé. A cada página o autor nos apresenta aos horrores cometidos pelos sionistas para expulsar os/as palestinos/as de suas terras para que pudessem fundar um Estado judeu.

Nas duas viagens que fiz à Palestina vi fragmentos. Conheci parte considerável dos 700 quilômetros de muro, serpentes de concreto; as barreiras militares. Escutei tiros que executaram um jovem na Cidade Velha de Jerusalém, ritual de morte que acontece quase todos os dias nas barreiras militares. Acompanhei e chorei com os moradores de Silwan (bairro palestino em Jerusalém Oriental) que tiveram suas casas demolidas. Conversei com crianças que tinham sido presas pelo Estado de Israel. Visitei alguns campos de refugiados. Faltava, contudo,

1 Departamento de Sociologia - Universidade de Brasília (UnB) - Brasília - Distrito Federal - Brasil - berenice.bento1@gmail.com 
ligar os vários pontos dos múltiplos atos de terror cometidos pelo Estado de Israel contra o povo palestino. Tão logo voltei ao Brasil, em janeiro de 2017, 0 livro de Ilan Pappé foi lançado. Este livro me deu um quadro histórico mais coerente e completo, que seria impossível de alcançar apenas pela dimensão da experiência. O que eu tinha assistido era, de fato, a continuidade da política iniciada em 1947 pelo futuro Estado de Israel: eu vi a continuidade da limpeza étnica da Palestina.

Um dos principais mitos que tenta justificar a existência de Israel se fundamenta no lema "Uma terra sem povo para um povo sem terra". A narrativa sionista é mais ou menos assim: "judeus miseráveis, perseguidos pelos antissemitas na Europa, finalmente, voltam para suas terras ancestrais. Encontraram terras desocupadas e, com seu trabalho, fizeram da terra seca brotar a abundância. Cercado de inimigos por todos os lados, os/as heroicos/as soldados/as judeus/judias resistiram, lutaram e fundaram o glorioso Estado de Israel!”. Após a pesquisa de Ilan Pappé, este mito foi definitivamente destruído.

A tese da limpeza étnica não é nova. Walid Khalidi, por exemplo, nos seus escritos, já seguia este caminho. Em sua obra-prima, Una Historia de los Palestinos a traves de la fotografia 1876-1948, Khalidi nos apresenta uma Palestina pulsante, com uma vida urbana conectada com grandes centros culturais e econômicos do mundo. $\mathrm{O}$ autor combina vários elementos narrativos em seu livro: fotografias, mapas, dados censitários e textos analíticos. A própria palavra sintese, usada pelos/as palestinos/as para se referir ao que lhes aconteceu, principalmente a partir de novembro de 1947, Nakba (catástrofe), nos revela que a tese de limpeza étnica não é nova.

Qual seria, então, a singularidade da obra de Pappé e por que sua leitura deve ser obrigatória para todos/as que estão conectados/as com a luta do povo palestino e/ou interessados/as em entender os mecanismos de dominação do neocolonialismo materializados nas políticas do Estado de Israel? Pela primeira vez, um pesquisador entra na alma do projeto sionista: vale-se dos arquivos da Haganá, das FDI (Forças de Defesa de Israel), arquivos centrais sionistas, registro das reuniões da Consultoria, diário e os arquivos pessoais de Ben-Gurion. Com rigor científico cirúrgico, o autor nos apresenta também cartas, documentos da ONU, repercussão em jornais de alguns dos massacres cometidos contra o povo palestino, arquivos da Cruz Vermelha. Além da descrição e análise histórica dos fatos, o livro ainda mostra fotos, cronologia dos fatos principais, mapas e um apartado com centenas de notas explicativas das fontes consultadas. São estas notas que garantem o rigor científico e o compromisso com a verdade. São centenas, iguais à Nota 5 (Capítulo 6): "Isso estava 
nas 'Ordens operacionais para as brigadas de acordo com o Plano Dalet', Arquivos das FDI, 22/79/1.303" (p. 313).

No primeiro capítulo, o historiador irá apresentar o conceito de "limpeza étnica" aceita por todos os organismos internacionais como "um esforço para deixar homogêneo um país de etnias mistas, expulsando e transformando em refugiados um determinado grupo de pessoas" (p. 23). Logo depois, nos conduzirá aos antecedentes históricos do projeto sionista de construção de um Estado para os judeus (por exemplo, a Declaração Balfour, de 1917) e nos apresentará aos "intelectuais orgânicos" da limpeza étnica, destacando-se o grande arquiteto Ben-Gurion.

Em carta ao filho, em 1937, Ben-Gurion antecipará o que iria acontecer: "Os árabes terão de ir, mas para fazê-lo acontecer, é necessário um momento oportuno, como uma guerra" (p. 43). Dez anos depois, em 1947, Yigael Yadin (outro importante quadro político-militar que planejou e executou a limpeza) afirmará: "os árabes palestinos não têm ninguém para organizá-los devidamente" (p. 42). Ou seja, a suposta guerra que Ben-Gurion já desejava em 1937 não aconteceu. Guerra só existe quando há um mínimo de equilíbrio na correlação de forças bélicas entre os inimigos. $\mathrm{O}$ que mostra a falsidade da retórica acionada sem timidez por Ben-Gurion de que os judeus na Palestina corriam risco de serem vítimas de um segundo Holocausto. Ao descrever os palestinos como nazistas, "a estratégia era uma manobra deliberada de relações públicas para garantir que, três anos depois do Holocausto, o ímpeto dos soldados judeus não vacilasse quando eram ordenados a limpar, matar e destruir outros seres humanos" (p. 93).

Foram três planos, ao todo, para realizar a limpeza étnica (Plano A, 1937; Plano B, 1946 e que passou a integrar o Plano C, de 1948). No entanto, o mais minucioso e melhor estruturado foi o Plano Dalet ("D" em hebraico). Assim, "alguns dias depois de escrito, o Plano D foi distribuído entre os comandantes das 12 brigadas incorporadas agora à Haganá. Junto à lista recebida vinha uma descrição detalhada dos vilarejos no seu raio de ação e de seu destino imanente: ocupação, destruição e expulsão. Os documentos israelenses liberados pelo arquivo das Forças de Defesa de Israel, no fim dos anos 1990, mostram claramente que, ao contrário das alegações feitas por historiadores como Benny Morris [historiador israelense], o Plano Dalet foi entregue aos comandantes de brigadas não como diretrizes gerais, mas como categóricas ordens para a ação" (p. 103).

No Capítulo 5, Pappé descreve e analisa a execução do Plano D mês a mês. O nome das Operações, os vilarejos capturados e destruídos, os massacres, o 
poder bélico da Haganá (mais de 50 mil soldados) em contraposição ao total desamparo dos/as palestinos/as. Foi durante a execução do Plano D que aconteceu o famoso massacre de Deir Yassin, "um cordial vilarejo pastoril que havia conseguido um pacto de não agressão com a Haganá de Jerusalém” (p. 110). Cerca de 170 habitantes foram brutalmente assassinados; dentre eles, 30 bebês.

As ordens eram claras: "matem qualquer árabe que encontrarem, incendeiem todos os objetos voláteis e derrubem as porta com explosivos" (p. 115). Eram as ordens daquele que se tornaria o chefe de estado-maior do exército israelense, Mordechai Maklef. ${ }^{2}$

Foram necessários apenas alguns meses para destruir 531 vilarejos, 11 bairros urbanos e mandar 800 mil palestinos/as para o exílio. Dos vilarejos destruídos, 31 foram massacrados, vítimas de carnificinas, entre eles: Nasr al-Din, Khisas, Safsaf, Sa’sa, Hussayniyya, Ayn Al-Zaytun, Tantura. Em relação à Tantura, décadas depois, Eli Shimoni, oficial da Brigada Alexandroni, admitiria: "Não tenho dúvida de que ocorreu um massacre em Tantura. Não saí por aí anunciando-o aos quatro ventos. Não é exatamente algo para se orgulhar" (p. 147). Não se sabe exatamente quantas pessoas foram executadas. Alguns falam de 85; outros, de 125. Em Tantura, "quando a carnificina acabou no vilarejo, com as execuções encerradas, dois palestinos receberam a ordem de cavar uma cova coletiva sob a supervisão de Mordechai Sokoler, de Zikhron Yaacov, dono das escavadeiras trazidas para realizar o trabalho macabro. Em 1999, ele disse que se lembrava de haver enterrado 230 corpos; tinha claro o número exato: 'eu os depus na cova, um a um"' (p. 156).

E os massacres seguem. Em Lydd: "As fontes palestinas narram que na mesquita e nas ruas ao redor, onde as forças judaicas fizeram mais uma onda de matança e pilhagem, 426 homens, mulheres e crianças foram mortos (176 mortos foram encontrados na mesquita). No dia seguinte, 14 de julho, os soldados judeus foram de casa em casa tirando as pessoas para a rua e empurrando cerca de 50 mil delas para fora da cidade, em direção à Cisjordânia (mais da metade já era refugiada de outros vilarejos próximos)" (p. 203). ${ }^{3}$

2 Sugiro que o livro de Ilan Pappé, como metodologia de leitura, tenha como suporte visual os mapas interativos produzidos pela ONG israelense Zochrot (http://zochrot.org). É possível encontrar informações dos vilarejos destruídos, dos massacres e um mapa com os atuais 54 campos de refugiados. Um terceiro suporte é o site <www.palestineremembered.com>, em que é possível ler depoimentos de palestinos/as que tiveram a vida de suas famílias destruídas pela limpeza étnica.

3 No exato momento em que escrevo esta resenha, acabo de saber que pesquisadores encontraram, em 26/04/17, no distrito de Jaffa (Tel Aviv), seis valas comuns que podem conter cerca de 600 corpos de palestinos/as que foram massacrados em 1948. Ver: <http://www.dailymail.co.uk/news/article-2334205/ Mass-grave-uncovered-containing-dozens-Palestinians-killed-1948-war-founded-Israel.html>. 
No entanto, foi no vilarejo Dawaymeh que as atrocidades superaram todas as pretéritas. Em 28 de outubro de 1948, 20 blindados israelenses entraram no vilarejo. Em pouco tempo, a chacina foi consumada. Estima-se que 455 pessoas foram assassinadas, sendo 170 mulheres e crianças. Os relatos, produzidos pelos próprios soldados, são estarrecedores: "bebês com crânios rachados, mulheres estupradas ou queimadas vivas nas suas casas e homens esfaqueados até a morte. Esses relatórios não foram elaborações a posteriori, mas depoimentos de testemunhos oculares enviados ao Alto Comando em questão de poucos dias após o fato" (p. 232). Os métodos utilizados não eram essencialmente diferentes de uma operação militar para a outra: pilhagem e roubo dos bens materiais, estupros, assassinatos, demolições, agressões, incêndios, campos de trabalho forçado, envenenamento de fontes de água.

Em 1950, a situação dos/as palestinos/as já era tão trágica que a ONU criou a Agência das Nações Unidas para Ajuda e Emprego (UNRWA - sigla em inglês) que se dedica, exclusivamente, aos/às palestinos/as refugiados/as. Os/as filhos/ as da diáspora palestina estão espalhados pelo mundo. Em novembro de 1948, a ONU aprovou a Resolução 194, que garante aos/às refugiados/as - que atualmente são 5,2 milhões - o direito de retorno às suas casas na Palestina. Como tantas outras Resoluções, o Estado de Israel nega-se a cumpri-la.

São gerações e gerações de palestinos/as espalhados/as em campos de refugiados. Muitos dos/as palestinos/as com quem conversei, moradores de campos de refugiados, conseguem apontar o local das casas de parentes que foram roubadas pelo Estado de Israel. Muitos ainda guardam as chaves de suas casas. Algumas vezes, as expõem como objetivo-símbolo dos seus sofrimentos e esperanças. Querem voltar para casa.

Em vários momentos, Ilan Pappé abre uma brecha na narrativa para expor sua subjetividade. Os achados científicos da pesquisa parecem ter produzido um tipo de perda do autor. É como se ele estivesse nos falando: "fui feito a partir de mentiras que me contaram". Entre outras passagens do livro, ele nos diz: "Como tantos outros pontos de belas paisagens dessa região [refere-se ao vilarejo de Qira, destruído em fevereiro de 1948], voltados à recreação e ao turismo, também esconde as ruínas de um vilarejo de 1948. Para minha própria vergonha, levei anos para descobri-lo" (p. 100).

O livro de Pappé tem sido uma poderosa arma para cumprir o objetivo que ele esboça já nas primeiras páginas. "Este livro foi escrito com a convicção profunda de que a limpeza étnica da Palestina precisa ficar enraizada na nossa memória e consciência como um crime contra a humanidade e de que deve ser excluído da lista de crimes supostos" (p. 25). 
Ao fim do livro, uma certeza: Israel é um imenso cemitério. Sob o "seu" solo, estão vilas, corpos, cemitérios palestinos, objetos e muitas histórias. Tudo escondido pelo silêncio sepulcral de um projeto colonial. Mas a história e seus fantasmas renascem de múltiplas formas. Pappé conta que o Fundo Nacional Judeu (FNJ) tentou cobrir as ruínas do vilarejo palestino de Mujaydil com dezenas de pinheiros. No entanto, "mais tarde, as visitas dos familiares de alguns dos aldeões originais da região descobriram que alguns dos pinheiros estavam literalmente rachados ao meio e que, no meio dos troncos rompidos, brotaram as oliveiras, desafiando abertamente a flora forânea plantada ali há 55 anos" (p. 262). A oliveira é o símbolo do povo palestino.

Qual o preço pela coragem de praticar a verdade, a parresía? Ilan Pappé sabe. Depois de publicar seu livro, em 2006, as perseguições e censuras por parte do Estado de Israel tornaram sua vida impossível. Ilan Pappé também é oliveira. Atualmente, vive exilado e está engajado na luta mundial de solidariedade ao povo palestino que clama pelo boicote, desinvestimento e sanções (BDS) ao Estado de Israel como forma desobrigá-lo a desocupar os territórios palestinos, fazê-lo parar com suas políticas de apartheid e, finalmente, reconhecer o direito de retorno dos/as palestinos/as refugiados/as.

\section{Referências}

KHALIDI, Walid. Una Historia de los Palestinos a traves de la fotografia 1876-1948. Les Editions de la Revue d'études palestiniennes: Paris. 1987.

DAILYMAIL. Mass grave uncovered containing dozens of Palestinians killed in 1948 war that founded Israel. Disponível em: $<$ http://www.dailymail.co.uk/news/article-2334205/Mass-grave-uncovered-containing-dozens-Palestinians-killed1948-war-founded-Israel.html>. Acesso em: 02 maio 2017.

ZOCHROT. Disponível em: <http://zochrot.org >. Acesso em: 02 maio 2017.

PALESTINE Remembered. Disponível em: <www.palestineremembered.com>. Acesso em: 02 maio 2017.

Recebido em 21/05/2017

Aprovado em 20/06/2017

\section{Como citar esta resenha:}

BENTO, Berenice. Ilan Pappé: história e verdade. Contemporânea - Revista de Sociologia da UFSCar, v. 7, n. 2, jul.- dez. 2017, pp. 523-528. 